\title{
CARBON FIBER-REINFORCED POLYMERS AS A TENSILE REINFORCEMENT OF THE Pinus elliotti AND Manilkara huberi WOOD SPECIES
}

\author{
Cintia Grazielle Alves dos Santos Bravo ${ }^{1}$, Luiz Antonio Melgaço Nunes Branco ${ }^{2}$, Eduardo Chahud ${ }^{3}$, \\ Vinicius Borges de Moura Aquino $^{4, \star}$, Alfredo Manuel Pereira Geraldes Dias ${ }^{5}$, Andre Luis Christoforo ${ }^{4}$, \\ Francisco Antonio Rocco Lahr ${ }^{6}$
}

\begin{abstract}
In wood structures, the elements subjected to bending stresses, such as the beams, present a fracture initiated in the tensile region, and under these conditions, the use of laminated composite materials is presented as an alternative solution in the form of repair or reinforcement. This research aimed to evaluate the influence of the use of carbon fibers laminated composites in tensile reinforcement in the direction parallel to grain of Pinus elliotti and Manilkara huberi wood species. The Viapol two-component epoxy adhesive was used in the lamination and fixation of the unidirectional carbon fiber in the wood species. Ten specimens with no defects (reference) and 10 specimens were prepared for each crack length $(25$ and $50 \mathrm{~mm})$ with and without the reinforcement $(60 \mathrm{~mm} \times 50 \mathrm{~mm})$ by the laminated composite. The tensile tests were performed in accordance with the requirements of the Brazilian standard ABNT NBR 7190 (1997). From the results of the statistical analysis, the use of the carbon fiber composite was able to restore the tensile strength of the cracked samples (partial or total) in relation to samples without defects, demonstrating the potential of the laminates in carbon fibers as an alternative solution in repair for both wood species.
\end{abstract}

Keywords: Damaged structures, laminated composites, reinforcement, carbon fiber epoxy adhesive, tension strength parallel.

\section{INTRODUCTION}

Wood is a natural and renewable source material (Dadzie and Amoah 2015, Beech et al. 2017) and presents a good relation between mechanical strength and density (Komariah et al. 2015, Aquino et al. 2018), which makes it suitable for use in rural and civil buildings (Motta et al. 2014).

The timber structures, if not properly treated for physical and biological attacks, such as climate change, moisture change, can present problems such as cracks, which may compromise the purposes for which they were designed (Dias and Lahr 2004, Christoforo et al. 2017, Sander et al. 2017).

The problems caused by biological and physical attacks on wood structures due to moisture change and the effect of long-term load on timber creep, such as cracks and great deflection on structural parts, may be

\footnotetext{
1Department of Civil Engineering, Estacio University, Belo Horizonte, Brazil.

${ }^{2}$ Department of Civil Engineering, FUMEC University, Belo Horizonte, Brazil.

${ }^{3}$ Department of Civil Engineering, Federal University of Minas Gerais, Belo Horizonte, Brazil.

${ }^{4}$ Department of Civil Engineer, Federal University of São Carlos, São Carlos, Brazil.

${ }^{5}$ Department of Civil Engineering, University of Coimbra, Coimbra, Portugal.

${ }^{6}$ Department of Structures Engineering, University of São Paulo, São Carlos, Brazil.

•Corresponding author: aquino.vini@hotmail.com

Received: 19.12.2018 Accepted: 05.10.2019
} 
explained by the natural source and behavior of wood, compromise the use of running structure and safety conditions for users (Franke et al. 2015, Fernando et al. 2016).

An alternative to repair (recovery of the original load capacity of the undamaged element) or reinforce (increase of the original load capacity of the undamaged element) wood structures, among other materials, consist on the use of composite materials (Bertolini et al. 2014, Miotto and Dias 2015, Carvalho et al. 2016, Fernando et al. 2016), laminates of carbon fibers (Fiorelli and Dias 2003, Garcia et al., 2013), because they have elevated mechanical strength and can contribute significantly in tensioned regions of structural elements of wood subject in bending, elevating its tensile strength and stiffness, since bending failure begins by tension. (Franke et al. 2015, Grazide et al. 2015).

There are several studies using carbon fibers as reinforcement in structural timber (Micelli et al. 2005, Biscaia et al. 2017, Rescalvo et al. 2018a, Rescalvo et al. 2018b), with emphasis on its use in engineered products, and it should be noted that much of these studies has been developed in several countries, in which wood species are naturally different and adhesives as well.

In Brazil, considering the amount of wood species being commercialized for the construction market, among them, Manilkara huberi (Dias and Lahr 2004) and Pinus elliotti (ABNT NBR 7190 1997), the understanding of how reinforcement by laminated composites in carbon fibers interacts with these species is important in the analysis of restoration of damaged structures. It is worth mentioning that in the Brazilian literature most of the work developed with the use of synthetic laminates in the repair or reinforcement of structures of wood and engineered wood-based materials consists of glass fiber composites (Fiorelli and Dias 2005, Miotto and Dias 2006, Buligon et al. 2015, Sales et al. 2017).

This research aimed to evaluate the influence of the use of unidirectional laminated composites on carbon fibers as repair or reinforcement in wood specimens of the wood species Manilkara huberi and Pinus elliotti tested in tension parallel to the fibers. The results obtained here are important for the understanding of the efficiency or not of the use of composites in carbon fibers for the evaluated wood species.

\section{MATERIALS AND METHODS}

The woods of Pinus elliotti var elliotti and Manilkara huberi were adequately stocked, presenting moisture content close to $12 \%$, which consists of the equilibrium humidity established by the Brazilian standard ABNT NBR 7190 (1997).

The apparent density $\left(\rho_{\text {ap }}\right)$ and the tensile strength parallel to the fibers $\left(f_{t 0}\right)$ were obtained according to the assumptions and methods of calculation of the referred Brazilian standard, and it should be noted that the geometry of the specimens was considered rectangular $(1 \times 5 \mathrm{~cm})$ and $40 \mathrm{~cm}$ in length, with the length of the contact of each pair of claws (apparatus for the tensile test) with the specimens being $8 \mathrm{~cm}$. The tensile tests (Figure 1) on the test specimens were performed with the aid of an EMC® test machine with $100 \mathrm{kN}$ load capacity.

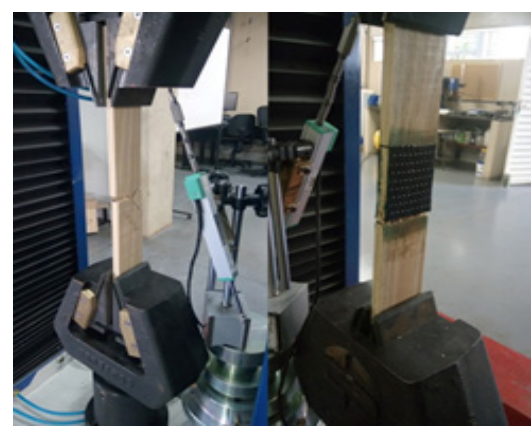

Figure 1: Tensile test for determination of tensile strength in the parallel direction in wood specimen of $\mathrm{Pi}$ nus elliotti var. elliotti partially cracked. 
In one face of the test specimens $(50 \times 400 \times 10 \mathrm{~mm})$ it was created a $2-\mathrm{mm}$ - thick and deep cracks and 25 $\mathrm{mm}(50 \%$ width - Figure $2 \mathrm{a})$ and $50 \mathrm{~mm}(100 \%$ width - Figure $2 \mathrm{~b})$, simulating defects in the wood and inducing the beginning of crack propagation near the midpoint. Ten (10) specimens with no defects (reference) and 10 specimens were prepared for each crack length $(25$ and $50 \mathrm{~mm})$ with and without the reinforcement $(60 \mathrm{~mm}$ length $\times 50 \mathrm{~mm}$ width) by the laminated composite fixed on both sides (Figure 2c), resulting in five distinct experimental treatments (Tr) (Table 1) and a total of 50 test specimens in all for the tensile tests.

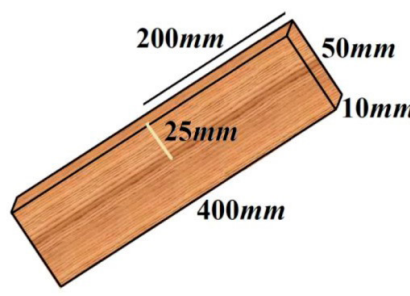

(a)

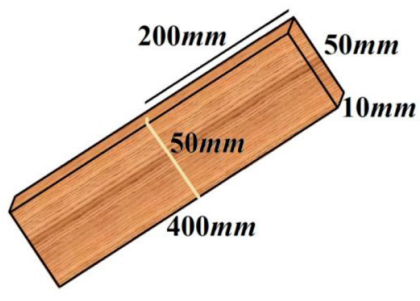

(b)

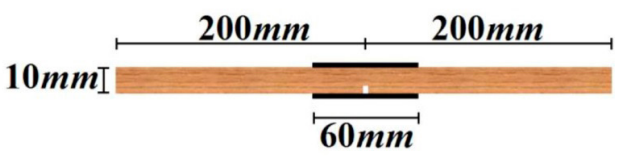

(c)

Figure 2: Partially fissured specimens (a) and fully cracked (b) on one side, reinforced by the carbon fiber laminated composite on both sides (c).

Table 1: Outlined experimental treatments.

\begin{tabular}{|c|c|}
\hline Treatments (Tr) & Description \\
\hline Ref & No defect and no reinforcement \\
\hline 1 & Partial crack without reinforcement \\
\hline 2 & Total crack without reinforcement \\
\hline 3 & Partial crack with reinforcement \\
\hline 4 & Total crack with reinforcement \\
\hline
\end{tabular}

The unidirectional carbon fiber fabric (Figure 3) used in the lamination and fixation in the specimens came from the manufacturer Viapol (Viapol Carbon CFW 300), recommended for structural reinforcements, with the fibers of the fabric being oriented parallel to the fibers of the wood. This unidirectional carbon fiber fabric has grammage of $0,300 \mathrm{~kg} / \mathrm{m}^{2}$, thickness of $0,166 \mathrm{~mm}$ tensile strength of $4900 \mathrm{MPa}$, modulus of elasticity of 230 $\mathrm{GPa}$ and elongation at break of $2,1 \%$.

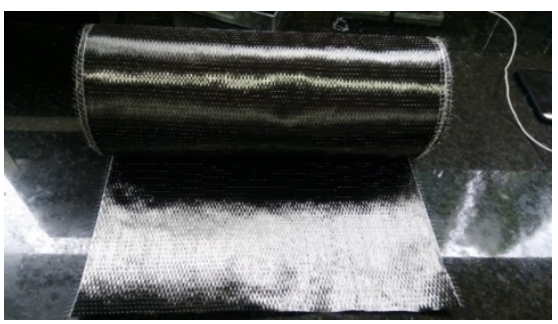

Figure 3: Unidirectional carbon fiber Viapol Carbon CFW 300. 
The adhesive and matrix phase of the laminated composites consists of resin and hardener, marketed under the name of Viapol Carbon Saturating, the same supplier of carbon fiber, consisting of a bicomponent epoxy resin. The hardener was added to the resin in the ratio 2:1 as indicated by the manufacturer. Blending and curing of the resin was performed at room temperature. According to the manufacturer, complete cure of the adhesive at room temperature occurs after 7 days.

The fibers were cut $6 \mathrm{~cm}$ long (Figure 2c) and $5 \mathrm{~cm}$ wide (coincident with the width of the specimens), resulting in a bonding area of $0,003 \mathrm{~m}^{2}$. Two pieces of carbon fiber $(6 \times 5 \mathrm{~cm})$ were glued on each face and in the central region of the fissured specimens. It was used $70 \%$ by mass of the bicomponent resin in relation to the mass of the fabrics in fixed carbon fibers, as performed by Ferreira et al. (2014).

To increase the adhesion of the composite, the surface preparation was performed after the generation of the cracks in the test specimens (Ferreira et al. 2014). Demarcated gluing regions, the sequence was itself used sandpaper to wood on both sides in order to increase the surface area and to remove oil residues and any types of impurities which could affect the adhesion of the bicomponent epoxy adhesive with wood.

After the preparation of the surface $(6 \times 5 \mathrm{~cm})$ by sanding, the bicomponent epoxy adhesive was spread (Figure 4a) evenly with the aid of a manual roller (Figure 4b). The unidirectional carbon fiber fabric was properly positioned on the adhesive surface (Figure 4c), and the roll was again applied onto the composite to ensure even spread of the adhesive. The specimens were tested after 10 days the lamination of the specimens.

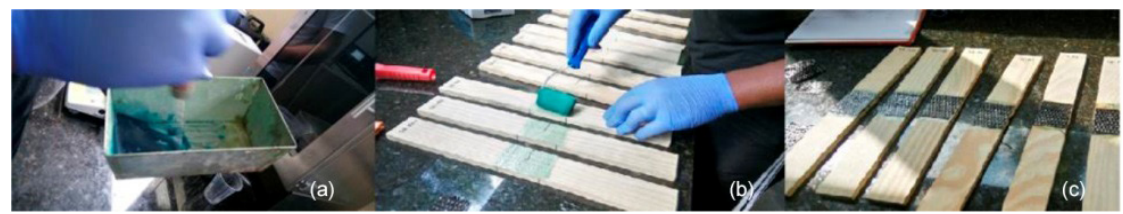

Figure 4: Roller for uniform spreading of bicomponent epoxy adhesive on the surfaces of fissured test specimens (a), dispersion of the resin in the regions of fixation of the composite (b), composite fixed to the wood specimens of Pinus elliotti. (c).

The Tukey test (at the 5\% level of significance) was used to evaluate the influence of composite use as repair or reinforcement on the fissured specimens (partially and totally) of both wood species. From the Tukey test, A denotes the group with the highest mean value, B the second highest mean value and so on, and equal letters imply treatments with statistically equivalent means.

Anderson-Darling normality tests and Bartlett's homogeneity of variances were used to verify the assumptions of the Tukey test. By the formulation of the tests ( $5 \%$ of significance), P-value (probability P) greater or 0,05 implies in the normality and homogeneity of the variances, validating the Tukey test results.

\section{RESULTS AND DISCUSSION}

The mean value and coefficient of variation $(\mathrm{CV})$ of the apparent density $\left(\rho_{\text {ap }}\right)$ for the Pinus elliotti var elliotti and Manilkara huberi woods were $\rho_{\text {ap }}=542,63 \mathrm{~kg} / \mathrm{m}^{3}$ and $\mathrm{CV}=6,23 \%$ and $\rho_{\text {ap }}=953,22 \mathrm{~kg} / \mathrm{m}^{3}$ and CV $=8,57 \%$, respectively. Figure 5 shows the mean values, extreme coefficient of variation (CV) values, mean confidence intervals (at 95\% confidence level) and Tukey test results (5\% significance) for tension parallel to the fibers $\left(\mathrm{f}_{\mathrm{t} 0}\right)$ of the five experimental treatments $(\mathrm{Tr})$ and for the two evaluated wood species. 

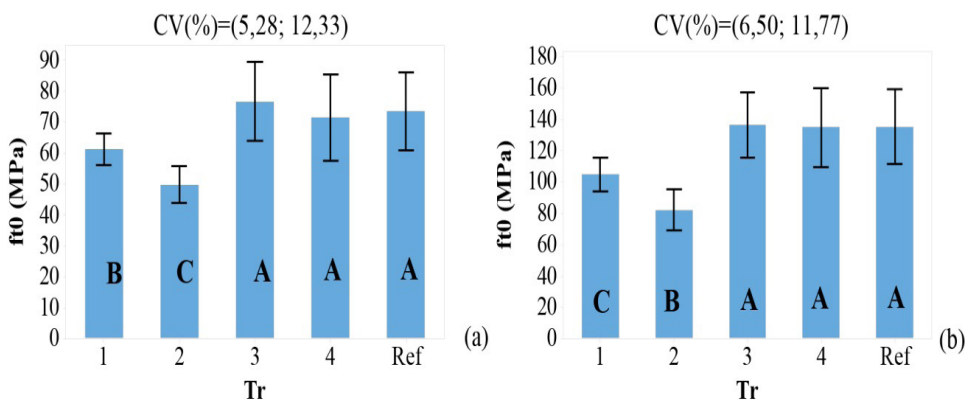

Figure 5: Results of Tukey test for $\mathrm{f}_{\text {to }}$ referent to the outlined experimental treatments: Pinus elliotti (a), Manikara huberi (b) wood species.

The mean value (reference values) of the tensile strength parallel to the fibers of Pinus elliotti obtained in the present study is equal to $73,38 \mathrm{MPa}$, with mean confidence interval $(\mathrm{CI})$ equal to $\mathrm{CI}=(60,72 ; 86,03 \mathrm{MPa})$. The average value of $f_{t 0}$ of Pinus elliotti presented in the Brazilian standard ABNT NBR 7190 (1997) is 66 $\mathrm{MPa}$, and belongs to the confidence interval found here.

The mean value (reference values) of $\mathrm{f}_{\text {t0 }}$ of Manilkara huberi wood in this work was 135,34 MPa, with mean confidence interval $(\mathrm{CI})$ equal to $\mathrm{CI}=(111,33 ; 159,35 \mathrm{MPa})$. The mean value of $\mathrm{f}_{\mathrm{t} 0}$ of Manilkara huberi wood specie from Dias and Lahr (2004) research is $139 \mathrm{MPa}$, which is consistent to the confidence interval determined here.

The highest values of the coefficients of variation for both wood species were lower than the $28 \%$ established by the Brazilian standard ABNT NBR 7190 (1997) for tangential requests.

The lower amplitude of the confidence intervals (lower variability) for both species was derived from the conditions of partial and integral crack generated on the surface of the non-reinforced samples $(\operatorname{Tr} 1$ and 2), which eventually induced the rupture process near the midpoint. The insertion of the fissure (stress concentrator) at the midpoint of the samples was responsible for inducing crack propagation nearby the midpoint of the samples (Figure 6a and Figure 7a).

The P-values of the Anderson Darling normality tests and Bartlett's homogeneity of variances ranged from 0,086 to 0,523 validating the Tukey test results (P-value $\geq 0,05$ ).

From Figure 1, the treatments $(\operatorname{Tr}) 3$ and 4, associated to the use of the reinforcement, and the reference condition (Ref) showed statistically equivalent results, i.e, the laminated composite was shown to be effective as structural repair for the species of wood of Pinus elliotti.

The inclusion of the carbon fiber composite $(\operatorname{Tr} 3)$ in the partially damaged Pinus elliotti wood specimens ( $\operatorname{Tr} 1)$ provided a $25,40 \%$ increase in $\mathrm{f}_{t 0}$. For the integrally fissured specimens $(\operatorname{Tr} 2)$, the inclusion of the laminate composite ( $\operatorname{Tr} 4$ ) was responsible for increasing the value of $f_{t 0}$ by $43,70 \%$, demonstrating the effective contribution of the laminated composites in carbon fibers for this wood specie.

In Figure 6 are presented fully cracked, reinforced $(\operatorname{Tr} 4)$ and non $(\operatorname{Tr} 2)$ reinforced test specimens after the tensile tests were performed parallel to the fibers of Pinus elliotti. 


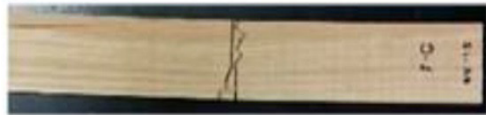

(a)

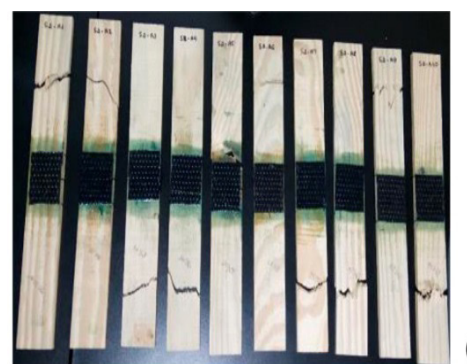

(b)

Figure 6: Test specimens of the Pinus elliotti wood after conducting the tensile tests in the direction parallel to the fibers - specimens with a surface crack along the entire width without (a) and with (b) the fiber carbon reinforcement.

For the fully cracked specimens, $70 \%$ ( 7 samples) presented failure close to the midpoint, and in the remaining 30\%, the failure occurred near the tension test apparatus. The insertion of the laminated composite (Figure 6b) modified the failure mode of the test specimens, where the fracture occurred preponderantly near the claws, thus, reinforcing the efficiency of the use of carbon fiber composites in Pinus elliotti var. elliotti.

For Manilkara huberi wood specie, as it happened with Pinus elliotti, the use of the carbon fiber composite in the fissured specimens (totally or partially) was able to restore the tensile strength (structural repair), noting the statistical equivalence of the means between the reference condition and the treatments $\operatorname{Tr} 3$ and $\operatorname{Tr}$ 4 by the Tukey test.

The inclusion of the carbon fiber composite (Tr3) in Manilkara huberi wood test specimens partially damaged ( $\operatorname{Tr} 1$ ) provided an increase of $30,42 \%$ on tension strength parallel to the grain. For the integrally fissured specimens ( $\operatorname{Tr} 2$ ), the inclusion of the laminated ( $\operatorname{Tr} 4$ ) was responsible for increasing the value of $\mathrm{f}_{\mathrm{t} 0}$ by $64,33 \%$ demonstrating the effective contribution of the laminated composites in carbon fibers also for this wood specie.

In Figure 7, reinforced ( $\operatorname{Tr} 4)$ and non-reinforced $(\operatorname{Tr} 2)$ fully cracked test specimens after the tensile tests were performed parallel to the fibers of the Manilkara huberi wood.

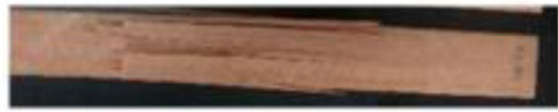

(a)

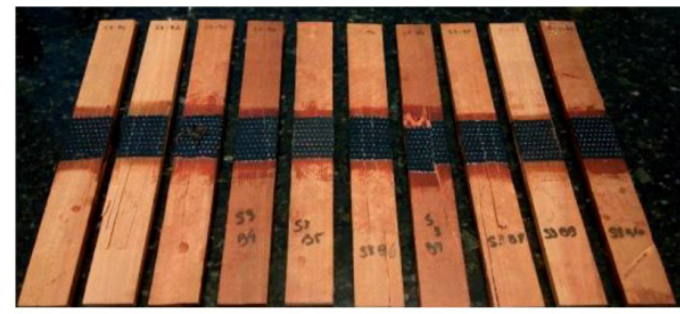

(b)

Figure 7: Test specimens of the Manilkara huberi wood after the tensile tests were carried out in the direction parallel to the fibers with a surface crack along the entire width without (a) and (b) with the carbon fiber composite.

From Figure $7 \mathrm{a}$, the failure occurred at the midpoint of the cracked samples over the entire width, with $60 \%$ showing failure at the midpoint, and the other specimens presented varied failure pattern. For the specimens of Figure $7 \mathrm{~b}(\operatorname{Tr} 4)$, the failure mode occurred in the direction of the fibers (longitudinal shear) and passing through the damaged and reinforced region, with the cracks starting at regions closer to the midpoint than in the case of woods of Pinus elliotti, which shows the higher interaction of the reinforcement with the wood of Manilkara huberi, a result that can also be noticed by the higher percentage value of increase of $\mathrm{f}_{\mathrm{t} 0}$ (from treatment 2 to 4) found for Manilkara huberi wood specie.

In particular, the bicomponent epoxy adhesive used in this research showed great compatibility with both wood species evaluated, with significantly different densities (density of Manilkara huberi approximately $75 \%$ higher than that of Pinus elliotti), and with respect to the length of $(60 \mathrm{~mm})$, this was enough for the redistribution of the efforts in the cracked regions. 


\section{CONCLUSIONS}

The results of this research allow us to conclude:

The carbon fiber laminate composite and bicomponent epoxy matrix were able to restore the tensile strength of partially and totally cracked specimens, demonstrating the efficiency of this reinforcement for both wood species evaluated, which indicates the use of laminates in carbon fibers as alternatives in the repair of wood structures;

The inclusion of the carbon fiber composite in the fully fissured Pinus elliotti and Manilkara huberi wood specimens provided increases of $43,70 \%$ and $64,33 \%$ in the tensile strength parallel to the grain, respectively;

By restoring the tensile strength values in the direction parallel to the fibers of both wood species, the length of $60 \mathrm{~mm}$ established for the fixation of the laminated composite in the specimens was enough for the redistribution of the efforts in the region of the cracks;

The inclusion of the laminated composites in carbon fibers in the cracked regions modified the failure pattern of the evaluated specimens, where the cracking began to occur in regions distant from the midpoint;

The good compatibility of the bicomponent epoxy adhesive used with the evaluated wood species was evidenced by the failure to start in the wood and not in the interface between the laminate and the wood.

\section{REFERENCES}

Aquino, V.B.M.; Almeida, J.P.B.; Almeida, D.H.; Almeida, T.H.; Panzera, T.H.; Christoforo, A.L.; Lahr, F.A. R. 2018. Physical and mechanical characterization of Copaifera $s p$. wood specie. International Journal of Materials Engineering 8(3): 55-58. https://doi.org/10.5923/j.ijme.20180803.03.

ABNT NBR. 1997. Projeto de Estruturas de Madeira. ABNT NBR 7190. 1997. Rio de Janeiro.

Beech, E.; Rivers, M.; Oldfield, S.; Smith, P.P. 2017. Global tree search: the first complete global database of tree species and country distributions. Journal of Sustainable Forestry 36(5): 454-489. https://doi.org /10.1080/10549811.2017.1310049.

Bertolini, M.S.; Almeida, D.H.; Icimoto, F.H.; Ferro, F.S.; Christoforo, A.L.; Lahr, F.A.R. 2014. Emprego de resina epóxi em vigas danificadas de madeira de Pinus elliottii. Ambiente Construído 14: 121-129. https://doi.org/10.1590/S1678-86212014000300010.

Biscaia, H.C.; Chastre, C.; Cruz, D.; Franco, N. 2017. Flexural strengthening of old timber floors with laminated carbon fiber-reinforced polymers. Journal of Composites for Construction 21(1): 04016073.

Buligon, E.A.; Haselein, C.R.; Gatto, D.A.; Santini, E.J.; Rauber. R.; Berger, C. 2015. Propriedades físico-mecânicas de painéis de lâminas paralelas reforçados com PRFV. Ciência Florestal 25(3): 731-741. https://doi.org/10.5902/1980509819676.

Carvalho, A.L.C.; Leila, F.M.; Dias, A.M.S.; Christoforo, A.L.; Silva, D.A.L.; Silveira, M.E.; Rocco, F.A.L. 2016. Numerical Analyses of Timber Columns Reinforced by Particulate Composite Material. The Open Construction and Building Technology Journal 10: 442-449.

Christoforo, A.L.; Panzera, T.H.; Araujo, V.A.; Fiorelli, J.; Lahr, F.A.R. 2017. Timber beam repair based on polymer-cementitious blends. Engenharia Agrícola 37: 366-375. http://dx.doi.org/10.1590/18094430-eng.agric.v37n2p366-375/2017.

Dadzie, P.K.; Amoah, M. 2015. Density, some anatomical properties and natural durability of stem and branch wood of two tropical hardwood species for ground applications. European Journal of Wood and Wood Products 73(6): 759-773. https://doi.org/10.1007/s00107-015-0925-x.

Dias, F.M.; Lahr, F.A.R. 2004. Estimativa de propriedades de resistência e de rigidez da madeira através da densidade aparente. Scientia Forestalis 65:102-113. 
Fernando, D.; Frangi, A.; Kobel, P. 2016. Behaviour of basalt fibre reinforced polymer strengthened timber laminates under tensile loading. Engineering Structures 117: 437-456. https://doi.org/10.1016/j.engstruct.2016.03.009.

Ferreira, M.B.; Correa, G.F.; Panzera, T.H.; Fiorelli, J.; Silva, V.R.V.; Rocco, F. A.L.; Christoforo, A.L. 2014. Numerical and Experimental Evaluation of the Use of a Glass Fiber Laminated Composite Materials as Reinforcement in Timber Beams. International Journal of Composite Materials 4: 73-82. https://doi. org/10.5923/j.cmaterials.20140402.06.

Fiorelli, J.; Dias, A.A. 2003. Analysis of the strength and stiffness of timber beams reinforced with carbon fiber and glass fiber. Materials Research 6(2): 193-202. http://dx.doi.org/10.1590/S1516-14392003000200014.

Fiorelli, J.; Dias, A.A. 2005. Avaliação da delaminação em peças de madeira laminada colada reforçadas com fibra de vidro. Revista Matéria 10(2): 241-249.

Franke, S.; Franke, B.; Harte, A.M. 2015. Failure modes and reinforcement techniques for timber beams - State of the art. Construction and Building Materials 97: 2-13. https://doi.org/10.1016/j.conbuildmat.2015.06.021.

Garcia, P.R.; Escamilla, A.C.; Garcia, M.N.G. 2013. Bending reinforcement of timber beams with composite carbon fiber and basalt fiber materials. Composites Part B 55 : 528-536. https://doi.org/10.1016/j.compositesb.2013.07.016.

Grazide, C.; Cointe, A.; Coureau, J-L.; Morel, S.; Dumail, J-F. 2015. Wood heterogeneities and failure load of timber structural elements: a statistical approach. Wood Science and Technology 49(2):421-440. https:// doi.org/10.1007/s00226-015-0706-z.

Komariah, R.N.; Hadi, Y.S.; Massijaya, M.Y.; Suryana, J. 2015. Physical-mechanical properties of glued laminated timber made from tropical small-diameter logs grown in Indonesia. Journal of the Korean Wood Science and Technology 43(2): 156-167.

Micelli, F.; Scialpi, V.; La Tegola, A.M. 2005. Flexural reinforcement of glulam timber beams and joints with carbon fiber-reinforced polymer rods. Journal of Composites for Construction 9(4):337-347.

Miotto, J.L.; Dias, A.A. 2006. Vigas mistas de concreto-MLC reforçadas com fibra de vidro. Cadernos de Engenharia de Estruturas 8: 73-76. https://doi.org/10.1016/j.compstruct.2015.03.054.

Miotto, J.L; Dias, A.A. 2015. Structural efficiency of full-scale timber-concrete composite beams strengthened with fiberglass reinforced polymer. Composite Structures 128: 145-154.

Motta, J.P.; Oliveira, J.T.S.; Braz, R.L.; Duarte, A.P.C.; Alves, R.C. 2014. Caracterização da madeira de quatro espécies florestais. Ciência Rural 44(12): 2186-2192. https://doi.org/10.1590/0103-8478cr20130479..

Rescalvo, F.J.; Suarez, E.; Valverde-Palacios, I.; Santiago-Zaragoza, J.M.; Gallego, A. 2018a. Health monitoring of timber beams retrofitted with carbon fiber composites via the acoustic emission technique. Composite Structures 206:392-402. https://doi.org/10.1016/j.compstruct.2018.08.068.

Rescalvo, F.J.; Valverde-Palacios, I.; Suarez, E.; Gallego, A. 2018b. Experimental and analytical analysis for bending load capacity of old timber beams with defects when reinforced with carbon fiber strips. Composite Structures 186: 29-38. https://doi.org/10.1016/j.compstruct.2017.11.078.

Sales, M.W.R.; Dalfré, G.M.; Sales, J.S.; Rabelo, R.B. 2017. Modelagem computacional do ensaio de tração de madeiras com reforço de laminados resinados de fibras de vidro e carbono. Revista Eletrônica de Educação da Faculdade Araguaia 11: 396-410.

Sander, S.C.; Panzera, T.H.; Christoforo, A.L; Fiorelli, J.; Lahr, F.A.R; Teixeira, S.F.R. 2017. Epoxy mortar timber beam upgrading. Internacional Wood Products Journal 1: 1-9. https://doi.org/10.1080/204264 45.2017.1335937. 